\title{
Pediatric Neuroblastoma and Anemia (Jehovah's Witness Case Report)
}

\author{
Khyati D Shah, MD ${ }^{1}$, Peter Anderson, MD, PhD² and Nathalie Carrizosa, PNP ${ }^{3}$ \\ ${ }^{1}$ Tri County Pediatrics, Rock Hill, SC, USA \\ ${ }^{2}$ Cleveland Clinic Pediatric Hematology, Oncology, and Bone Marrow Transplant, Cleveland Clinic Foundation, Cleveland OH, USA \\ ${ }^{3}$ Charlotte, USA
}

Submission: July 12, 2017; Published: August 10, 2017

*Corresponding author: Khyati Shah, Tri-County Pediatrics LLC, 165 Amendment Ave, \#102, Rock Hill, SC 29732, USA, Tel: 803-329-2700;

Email: drkhyati22@gmail.com

\begin{abstract}
Introduction: Neuroblastoma is the most common extra cranial solid tumor in young children and is derived from embryonic neural crest cells (i.e. is a neuroendocrine tumor) that can have variety of presentations including failure-to-thrive and gastrointestinal symptoms.

Case: A 13 month old whose parents are Jehovah's Witnesses presented with generalized edema and diarrhea. Laboratory evaluation and upper endoscopy results showed iron deficiency anemia and protein losing enteropathy. Additional imaging of abdomen and pelvis revealed a mass that encased the celiac vessels. Elevated VMA/HVA and CT and MIBG scan diagnosed neuroblastoma without metastases. Since no other sites of disease were present on scans or in the bone marrow, the classification was intermediate risk. Indications, risks, and alternatives of various treatment options were discussed in detail with the parents who wanted to avoid transfusions. Anemia was treated with intravenous and oral iron and darbopoetin. The toddler was treated with 10 cycles of risk-adapted chemotherapy which did not require transfusion (vincristine, cisplatin, and oral cyclophosphamide) followed by surgical removal of the mass. The patient remains in complete remission 4 years after diagnosis.

Discussion: Diarrhea, iron-deficiency anemia, and failure-to-thrive in an infant or toddler can be a presentation of neuroblastoma. Anemia associated with solid tumors in a Jehovah's Witness can be treated with intravenous iron sucrose, oral ferrous sulfate+Vitamin C, and darbopoetin. In intermediate risk cases, an effective chemotherapy regimen can be used without major reduction of red cell or platelet production to avoid red cell and/or platelet transfusions.

Keywords: Neuroblastoma; Anemia in Jehovah's witness; Darbopoetin; Tumor; Risk-adapted chemotherapy

Abbreviations: CT: Computed Tomography; MIBG: Metaiodobenzylguanidine; VMA: Vanillylmandelic Acid; HVA: Homovanillic Acid; INRG: International Neuroblastoma Risk Grouping
\end{abstract}

\section{Introduction}

Neuroblastoma is the most common extra cranial solid tumor in children, accounting for 7-8\% of all childhood cancers; outcomes after reduced chemotherapy for intermediate-risk neuroblastoma are good [1]. It usually presents as an abdominal mass, but sometimes may present with other systemic symptoms like vomiting, fever, malaise, lethargy, bone pain secondary to metastases. Rarely, neuroblastoma can cause chronic diarrhea caused by effects on the GI system of the various substances secreted by the tumor [2]. Iron deficiency is also a known cause of protein losing enteropathy [3].

We share our experience with an unusual presentation of neuroblastoma in a child with diarrhea and generalized edema, protein losing enteropathy, and severe iron deficiency anemia complicated by the family being Jehovah's Witnesses for whom blood transfusions are contraindicated because of religious beliefs. In this case transfusion was avoided; anemia was treated with iron sucrose, followed by oral ferrous sulfate + Vitamin C and darbopoetin. The child's intermediate-risk neuroblastoma was also successfully treated.

\section{Case Presentation}

A previously healthy 13 month old girl presented with abdominal distention and dependent edema for 2 days. She was in her usual state of good health until 1 week prior to presentation, when she developed acute watery diarrhea with 6-8 stools/day without blood in stool. On physical examination, she was alert, a febrile with minimal distress secondary to the abdominal distention. Her vital signs were within normal limits for age; she had gained 2 pounds within the last 3 days. Laboratory testing showed normal values for complete metabolic panel other than low protein and albumin $(2.9 / 1.5 \mathrm{gm} / \mathrm{dL})$. Total WBC count with differential was normal. UA was negative for proteinuria, abdominal ultrasound showed mild ascites. She continued to have lower extremity edema and ascites, most prominent in the morning upon waking.

Over the next 2 weeks, she became less playful and stopped walking. Her oral intake decreased and diarrhea worsened. Repeat labs showed microcytic anemia (MCV 75) with a 
hemoglobin level of $8 \mathrm{gm} / \mathrm{dL}$; serum iron was 8 . Total protein and albumin remained low (3.4/1.4). Upper endoscopy revealed normal morphology and stomach biopsy showed mild lamina propria edema. Stool studies showed elevated alpha-1-anti trypsin, indicating protein loss via GI tract.

Given the upper GI endoscopy results and stool studies, she was initially diagnosed with iron deficiency and protein losing enteropathy of unknown cause. Endoscopy biopsy results were negative for CMV infection, inflammation, celiac disease, lactase deficiency and allergies. Hematology/oncology was consulted because of poor po intake, anemia, and persistent abdominal distention with dependent edema. A CT scan of the abdomen/pelvis was done with oral and intravenous contrast and indicated an $8.1 \times 7.9 \times 7.8 \mathrm{~cm}$ mass encasing the aorta and the celiac artery. Bone marrow biopsy and aspirate did not show any evidence of malignancy. Intense MIBG uptake in the mass, no osseous uptake on bone or MIBG scan, and marked VMA/HVA elevation (149/437) confirmed diagnosis of intermediate-risk neuroblastoma in the abdomen without liver metastases or bone or marrow involvement.

Since intermediate neuroblastoma has an excellent prognosis with therapy [1], indications, risks and alternatives of various options to treat anemia and this malignancy were discussed with parents who are Jehovah's Witnesses. Initial treatment of iron deficiency was with iron sucrose $(1 \mathrm{mg} / \mathrm{kg}$ over 1 hour daily x 3 days) followed by oral ferrous sulfate plus vitamin $\mathrm{C}$ to promote absorption. Darbopoetin was also used to maintain increased red cell production while on chemotherapy. A chemotherapy regimen of vincristine+cisplatin every 3 weeks and daily oral cyclophosphamide was administered. Urinary VMA/HVA became normal in 3 months and the mass was $6.3 \times 5 \times 4.2 \mathrm{~cm}$. Within 6 months (10 cycles of chemotherapy), the mass size was $3.8 \times 3.2 \times 3 \mathrm{~cm}$. The child underwent surgery 6 weeks after completion of last cycle of chemotherapy. Both a pediatric surgeon and vascular surgeon participated in the operation Complete resection was achieved with total blood loss of about 5cc. Pathology showed $>99 \%$ necrosis and no viable tumor. Imaging after surgery has shown no evidence of recurrence. The little girl remains healthy and active $>3$ years after surgery (apparent durable remission).

\section{Discussion}

Neuroblastoma is an embryonal malignancy derived from the primitive cells of the sympathetic nervous system [4]. It is the most common extra-cranial solid tumor occurring in childhood and has a diverse clinical presentation and course depending on the tumor biology. The tumor can present itself anywhere in entire sympathetic nervous system; however, adrenal gland and abdominal (extra-adrenal) are the most common sites which are then followed by thoracic, cervical and pelvic sympathetic ganglia as the next most common areas. Unique features of these neuroendocrine tumors are the early age of onset, the high frequency of metastatic disease at diagnosis, and the tendency for spontaneous regression of tumors in infancy [5]. Signs and symptoms may vary depending on the site of origin of the tumor and include unexplained fever, weakness, abdominal pain, vomiting, diarrhea, weight loss, chronic fatigue, opsoclonusmyoclonus, lower extremity weakness (e.g. in case of spinal cord compression), and ecchymosis secondary to metastasis to the bones (e.g. orbit). Neuroblastomas are known to occasionally cause chronic diarrhea by poorly understood mechanisms of neurohumoral effects on bowel motility and secretions, but this tumor is generally not associated with protein losing enteropathy [6]. Staging is performed using bone marrow aspirate and biopsy, CT, bone and MIBG scans. Age, stage, histopathological grading, MYCN amplification and 11q aberration are important prognostic factors utilized in risk stratification and treatment decisions [6,7]. Risk-stratified chemotherapy and radiation has facilitated the reduction of chemotherapy and radiation toxicity for children with low and intermediate-risk disease.

Low-risk disease including Stage 1 and asymptomatic Stage 2 disease has an excellent prognosis with surgery alone Intermediate-risk disease consisting largely of difficult to resect and symptomatic Stage 2/3 disease and infants with Stage 4 disease have good outcome with cycles of chemotherapy followed by surgical resection. The role of radiotherapy in intermediate risk tumors is related to extent of resection, location, and risk of long term effects. The most commonly used chemotherapeutic agents in intermediate risk disease have been vincristine, cyclophosphamide, cisplatin, doxorubicin, carboplatin, topotecan, and ifosfamide. High-risk disease includes older children with Stage 4 disease and MYCN amplified tumor [6]. Advances in therapy for patients with high-risk disease include intensive induction chemotherapy and myeloablative chemotherapy, followed by the treatment of minimal residual disease using differentiation therapy and immunotherapy; these have improved 5-year overall survival to 50\% [5].

Surveillance studies during and after treatment are able to detect asymptomatic and unsuspected relapse using urinary VMA/HVA, 123I-MIBG scan, and/or CT or MRI. A multidisciplinary team is involved in the treatment, supportive care and follow-up of these children with neuroblastoma. Timely management of a potential problem detected during therapy and follow up visits will maximize health and the quality of life on therapy and after therapy. Our patient became healthy and has stayed healthy.

Our case is somewhat unique in that the high survival rate in intermediate risk disease would not warrant a court order for myelosuppressive therapy and surgery when acceptable alternatives for a Jehovah's Witness are possible. We achieved an excellent outcome following principles of care: reduction of size of tumor with risk-adapted chemotherapy, followed by careful surgical resection.

\section{References}

1. Baker DL, Schmidt ML, Cohn SL, Maris JM, London WB, et al. (2010) Outcome after reduced chemotherapy for intermediate-risk neuroblastoma. N Engl J Med 363: 1313-1323. 
2. Gerdes MD, Jeffrey S, Aaubrey J, Katz MD (1982) Neuroblastoma appearing as protein-losing enteropathy. Am J Dis Child 136: 10241025.

3. Nickerson HJ, Silberman T, Park RW, DeVries EO, Broste SK, et al (2000) Treatment of iron deficiency anemia and associated proteinlosing enteropathy in children. J Pediatr Hematol Oncol 22(1): 50-54.

4. Brodeur GM (2003) Neuroblastoma: biological insights into a clinical enigma. Nat Rev Cancer 3(3): 203-216.
5. Matthay KK, Maris JM, Schleiermacher G, Nakagawara A, Mackall CL, et al. (2016) Neuroblastoma. Nat Rev Dis Primers 2: 16078.

6. Bansal D, Totadri S, Chinnaswamy G, Agarwala S, Vora T, et al. (2017) Management of Neuroblastoma: ICMR Consensus Document Indian J Pediatr 84: 446-455.

7. Cohn SL, Pearson AD, London WB, Monclair T, Ambros PF, et al. (2009) The International Neuroblastoma Risk Group (INRG) classification system: an INRG Task Force report. J Clin Oncol 27: 289-297.

This work is licensed under Creative Commons Attribution 4.0 Licens

DOI: 10.19080/JTMP.2017.01.555569

\section{Your next submission with Juniper Publishers} will reach you the below assets

- Quality Editorial service

- Swift Peer Review

- Reprints availability

- E-prints Service

- Manuscript Podcast for convenient understanding

- Global attainment for your research

- Manuscript accessibility in different formats

( Pdf, E-pub, Full Text, Audio)

- Unceasing customer service

Track the below URL for one-step submission https://juniperpublishers.com/online-submission.php 